\title{
PROPAGACIÓN in vitro DE Leucocoryne sp. CV. "CARAVELLE"
}

\section{In vitro PROPAGATION OF Leucoryne sp. CV. "CARAVELLE"}

\author{
Fuentevilla, C.; Castro, M. y G. Verdugo. \\ Facultad de Agronomía, Pontificia Universidad Católica de Valparaíso. Casilla 4-D, Quillota. \\ E-mail: mcastro@ucv.cl
}

\section{INTRODUCCIÓN}

Como todo programa de mejora genética, este se sostiene en tres pilares: diversidad (natural o generada por cruzamientos), desarrollo de ejemplares con características deseables para un fin específico (que en este caso puede ser flor de corte, o bien para maceta) y la capacidad de multiplicar dichos ejemplares de tal modo de llegar a constituir un cultivar. Persiguiendo este último fin, la técnica de cultivo in vitro, se convierte en una herramienta eficaz para masificar los ejemplares iniciales, aumentando la cantidad de material vegetal con el cual trabajar en la siguiente etapa de la investigación. El órgano geófito de Leucocoryne es un bulbo esférico o algo ovalado, de 1,5 a $2,5 \mathrm{~cm}$ de diámetro, el que está cubierto exteriormente por membranas secas de color castaño y en su interior se encuentran hasta veinte túnicas carnosas. En la base del bulbo existe un disco del cual nacen muchas raíces fasciculadas. En su ápice se yergue el cuello, una estructura cilíndrica, formada por la base de las hojas que generalmente está rodeada de hojas secas, remanentes de años anteriores (Mansur et al., 2002). La reproducción vegetativa se produce por la formación de nuevos bulbillos que se originan en el disco basal del bulbo madre, como pequeñas estructuras, que en su ciclo vital, poco a poco se transformarán en nuevos bulbos (Mansur et al., 2002). Schiappacasse et al. (1999) se refieren a distintas técnicas artificiales, que aceleran la propagación vegetativa propia en especies geófitas. Entre ellas se encuentran el corte en cruz o "scoring", vaciado o "scooping" y "coring". Los tres métodos se aplican a bulbos tunicados, de preferencia en receso. Respecto de la propa- gación in vitro de Leucocoryne, existen escasos antecedentes.

El objetivo de esta investigación fue evaluar el comportamiento de individuos de Leucocoryne sp. cultivar Caravelle en las etapas de establecimiento, multiplicación y ganancia de peso de los bulbos, en condiciones in vitro.

\section{MATERIAL Y MÉTODOS}

La propagación in vitro se llevó a cabo en el Laboratorio de Propagación "Profesor Gregorio Rosenberg" de la Facultad de Agronomía de la Pontificia Universidad Católica de Valparaíso. Se utilizó explantes provenientes de bulbo que correspondían a la mitad de éste, obtenidos mediante un corte longitudinal. Luego, se establecieron en distintos medios de cultivo, previa desinfección de los bulbos, que fueron sumergidos durante 15 minutos en una solución de Captan: Benomilo de $1.8 \mathrm{gL}^{-1}$ de cada uno de estos fungicidas, 30 segundos en etanol al $70 \%$ y 15 minutos en hipoclorito de sodio al $1 \%$. Los tres medios de cultivo utilizados: M1, M2 y M3 constituidos por medio MS (Murasshine y Skoog, 1962) suplementado con distintas concentraciones de ANA (Ácido naftalenacético) y KIN (Kinetina).

\section{RESULTADOS Y CONCLUSIONES}

Los tres medios ensayados resultaron favorables para el establecimiento y multiplicación de los explantes siendo, aparentemente, mejor la respuesta en el medio 2 (MS adicionado con 0.1 $\mathrm{mgL}^{-1}$ de ANA y $2 \mathrm{mgL}^{-1}$ de KIN), con el que se obtuvo 17 bulbillos/explante, con un diámetro ecuatorial promedio de $7,94 \mathrm{~mm}$. 
En la etapa de incremento de peso se utilizó el medio MS adicionado con $60 \mathrm{gL}^{-1}$ de sacarosa Esto, basado en uno de los primeros informes relacionados con la microbulbificación sincronizada in vitro en ajos de sanidad controlada, el que fue realizado por Racca (1989) citado por Izquierdo y Quiones (2003). Este autor utiliza como medio basal MS a la mitad suplementado con $0.3 \mathrm{ppm}$ de ANA y $3 \mathrm{ppm}$ de 2 -ip, pero las pérdidas fueron superiores al $70 \%$ cuando se transfirieron las plántulas propagadas in vitro directamente a macetas. Este inconveniente se solucionó transfiriendo las vitroplantas después de la fase de multiplicación a un medio MS diluido a la mitad sin suplemento de auxinas ni citoquininas y suplementado con sacarosa. A los 90 días se obtuvo un $62 \%$ de bulbificación con $60 \mathrm{gL}^{-1}$ de sacarosa. Estos microbulbillos alcanzaron una sobrevivencia superior al $85 \%$ en campo, siempre y cuando su tamaño fuera superior a $3 \mathrm{~mm}$ de diámetro.

Los bulbos obtenidos correspondieron a calibres de bulbos de tamaño floral y sin presencia de raíces; lo que en concordancia con lo señalado por Boutherin y Bron (1994), quienes indican que las raíces nacidas in vitro son extremadamente frágiles y colocadas en contacto con un sustrato, mueren y sería necesario esperar la formación y el crecimiento de nuevas raíces para que la planta se nutra; dejaría material de fácil manipulación para su posterior aclimatación.

Respecto del rendimiento obtenido (número de bulbillos por explante) la tasa fue mayor en explantes provenientes de bulbo. Así también, explantes provenientes de la zona basal de la hoja, tendrían un mayor potencial para generar bulbillos, en relación con explantes provenientes de otras porciones de hoja.

\section{BIBLIOGRAFÍA}

BOUTHERIN, D.; BRON, G. 1994. Multiplicación de plantas hortícolas. Zaragoza, Acribia. 225p.

IZQUIERDO O.; QUIONES O. 2003. Obtención de semilla de ajo. (on line), www.utm.mx/temas/temas-docs/nfnotas15R2.pdf. Marzo 2003.

MANSUR, L.; ZOELLNER, O.; RIEDEMANN, P.; VERDUGO, G.; HARRISON, C. 2002. Leucocoryne, un género nativo chileno y su uso como planta de jardín. Valparaíso, Oficina de Transferencia Tecnológica Universidad Católica de Valparaíso. $49 \mathrm{p}$.

MURASHIGE, T.; SKOOG, F. 1962. A revised medium for rapid growth and bioassays with tobacco tissue cultures. Physiol. Plant. 15: 473- 497.

SCHIAPPACASSE, F.; YAÑES, P.; PEÑAILILLO, P. 1999 Propagación de geófitos nativos. FIA. Los geófitos nativos y su importancia en la floricultura. Talca. 12 noviembre 1999. pp. 11-26.

Agro Sur $34(1-2): 23-252006$

\title{
INDUCCIÓN Y DETECCIÓN DE AUTOPOLIPLOIDÍA EN Rhodophiala Presl.*
}

\section{INDUCTION AND DETECTION OF POLYPLOIDY IN Rhodophiala Presl.}

\author{
Muñoz, $\mathbf{M}^{\prime}$., Riegel, $\mathbf{R}^{1}$. Seemann, $\mathbf{P}^{1}$., Jara, $\mathbf{G}^{1}$., Schiappacasse, F., Peñailillo, $\mathbf{P}^{2}$., Basoalto, $\mathbf{A}^{2}$ \\ 'Instituto de Producción y Sanidad Vegetal, Facultad de Ciencias Agrarias. Universidad Aus- \\ tral de Chile. Casilla 567, Valdivia, Chile. E-mail: mamunoz@uach.cl \\ ${ }^{2}$ Departamento de Horticultura, Universidad de Talca, Casilla 747, Talca.
}

\section{INTRODUCCIÓN Y OBJETIVOS}

La duplicación cromosómica ha sido ampliamente utilizada en horticultura para obtener nuevas y/o mejorar características agronómicas. En especies de uso ornamental esta técnica ha permitido lograr flores de mayor tamaño y de texturas más intensas, así como un período de floración más prolongado. Para realizar un aumento de ploidía en vegetales, es frecuente el tratamiento de plántulas jóvenes en crecimiento activo con colchicina, un alcaloide natural con 